\title{
Del Río, F. (2020). Las filósofas tienen la palabra. Siglo XXI. 232 pp.
}

Caben pocas razones para dudar que las primeras dos décadas del siglo XXI serán recordadas en el futuro como decenios de transformación. No sabemos todavía cómo será el mundo en los años cincuenta de este siglo; sí sabemos que a inicios de los años veinte de los años dos mil apareció una pandemia que nos encerró a todas, que nos hizo patente nuestra vulnerabilidad, que sacudió nuestra concepción del Estado y su papel en la vida de las personas, por mencionar sólo algunas nuevas certezas. No sabemos cómo será el mundo en esos años; sabemos, sí, que la lucha de las mujeres ha tenido un repunte particularmente potente y significativo a lo largo de estos dos decenios. Nuestra voz, la voz femenina, ha empezado a hacer eco en rincones distintos y variados del orbe. En nuestro país hemos visto ocurrir los Encuentros Internacionales de Mujeres que Luchan en territorio zapatista; hemos visto a las jóvenes estudiantes tomar escuelas y facultades de la Universidad Nacional Autónoma de México, y vimos una marcha multitudinaria el 8 de marzo (justo antes del confinamiento) que pintó de morado a la Ciudad de México, además de que salpicó de colores femeninos al resto del país. Esto es por narrar sólo algunos de los acontecimientos más visibles de entre los sucesos más nombrados en torno a la movilización de las mujeres en el mundo. En este contexto aparece publicado el libro de Fanny del Río, que lleva por título Las filósofas tienen la palabra y que nos presenta diez entrevistas a diez mujeres filósofas que ejercen su labor en México (salvo una que lo hace en los Estados Unidos de América).

El interés de Fanny del Río por las mujeres tiene cierta trayectoria. En 2009 publicó una novela que lleva por título La verdadera historia de la Malinche, donde deja ya claro que la historia ha sido narrada, desde siempre, con la mirada de quien se dice triunfador y que (casi) siempre es hombre. La voz de la historia es masculina y los relatos que se nos trenzan en el cuerpo y nos van trazando como sociedades cargan con una perspectiva masculina silenciosa, pero potente e imponente. Su inquietud por mirar de otra manera, por empezar a decir el mundo en femenino, encuentra hoy un nicho propicio para ser propagada, para contagiarse. En este sentido, la aparición de Las filósofas tienen la palabra es extremadamente pertinente y exhibe una atinada sensibilidad frente a la realidad. En él se articula un sentir colectivo: es hora de que las mujeres, de que las filósofas, sean escuchadas; es hora de que se haga visible el valor de la filosofía hecha por ellas, de que se valore la 
perspectiva femenina en el quehacer arduo y abstracto que casi siempre acompaña a esta disciplina.

\section{El libro y sus lecturas}

Aunque la descripción que recién ofrecí del libro dice de él que es un conjunto de entrevistas, en realidad el volumen es mucho más que eso. Esto se hace patente al descubrir que puede ser leído, al menos, de tres distintas maneras. Una de ellas, la más inmediatamente relacionada con la descripción inicial, es como una narración de cómo algunas filósofas han pensado y vivido su labor en México, cómo decidieron estudiar o dedicarse a la filosofía, cómo era el mundo cuando tomaron su decisión, cómo han ido desarrollando su profesión en un mundo masculino. En esta descripción, el libro nos ofrece un vistazo al tipo de preocupaciones que llevaron a estas mujeres a hacer filosofía, al tipo de filosofía que les gusta y que hacen, incluso a algunas de las ideas que han defendido y sostenido como filósofas. Esta primera lectura es, como lo dice la misma Fanny, parte de un esfuerzo cada vez más colectivo por "consolidar un registro histórico de filósofas mexicanas" (p. 9), que no existe (y, sobre todo, que no existe de manera sistematizada) actualmente en las bibliotecas nacionales $\mathrm{u}$ otros espacios académicos.

La segunda lectura que, yo encuentro, puede hacerse de este libro es aquélla que lo comprende como un compromiso con la visibilización de las mujeres o, como dice Fanny, como un acto de responsabilidad ética y de justicia epistémica. Su autora nos recuerda, en la introducción al libro y a este respecto, que hoy día muchas filósofas estudian el fenómeno de la exclusión y el silenciamiento de las "mujeres en filosofía", y parte de la motivación y el fin de hacerlo es "rescatar del olvido la lista de mujeres que han producido escritos filosóficos a lo largo de la historia" (p. 9). La lista de estas últimas es muy larga y seguramente estará siempre incompleta: debe haber un número razonablemente grande de mujeres que han pensado, escrito y hecho filosofía a lo largo de la historia pero que nunca han dicho que lo han hecho; debe haber montones de papeles desaparecidos en el tránsito del tiempo sin que hayan siquiera sido vistos o mirados, un montón de ideas valiosas que se fueron al silencio del viento que se las llevó consigo. En este punto resulta de particular interés cómo empieza el libro: Del Río cita a la filósofa estadounidense Linda Lopez, quien se sorprendió al percatarse de que en ninguna de sus “clases de licenciatura, maestría y doctorado, había oído mencionar el 
nombre de ninguna mujer filósofa" (p. 9). El eco de esta frase me susurra todos los días al oído. En la Facultad de Filosofía y Letras de la UNAM teníamos muchas maestras mujeres; pocas nos enseñaban su propio pensamiento o el de otras mujeres. Recientemente, en una entrevista que me hicieron, me preguntaron a qué mujeres filósofas latinoamericanas leo regularmente. La respuesta, triste pero honesta, es que casi no leo mujeres filósofas. Este libro hace patente que nosotras, otras filósofas mujeres, tenemos ahora la obligación de rescatar lo rescatable, de hacer visible lo que nosotras mismas creamos. Este libro es también un enérgico llamado a los compañeros filósofos a leer el pensamiento de sus colegas mujeres, a estudiarlo y a enseñarlo. Este libro quizá abra una avenida para que la filosofía hecha por mujeres empiece a ser estudiada y nombrada en las clases, para que nos decidamos a formar una comunidad de filósofas que no sólo se leen entre sí, sino que además construyen pensamiento en común. Para que esta construcción se haga entre nosotras y con nuestros compañeros varones.

Finalmente, una tercera lectura posible es aquélla que lo ve como un documento histórico: un registro de la manera en que las mujeres hemos cambiado la manera de pensar acerca de nosotras mismas, acerca del lugar que ocupamos en la academia (en la sociedad, en el mundo), de la manera en que hemos sido tratadas y cómo merecemos ser tratadas. Desde mi perspectiva, ésta es una lectura que no es explícita, pero que ofrece un valor inmenso al texto en cuestión. En lo que sigue intentaré destacar cómo la conciencia de exclusión y silenciamiento es algo reciente. Muchas de las entrevistadas no reconocen el fenómeno o dicen que antes no lo pensaban como algo importante. La invisibilización era ella misma invisible y, por tanto, parecía un fenómeno inexistente. Éste, gracias - entre muchas otras cosas - a las movilizaciones mencionadas al inicio de esta reseña, es cada vez más nombrado y reconocido. Lo que ahora toca es erradicarlo de nuestras prácticas y relaciones académicas.

\section{Las entrevistadas}

Diez mujeres, diez filósofas conforman este texto. Casi todas fueron mis maestras (o me ha tocado mirarlas desempeñar papeles importantes en el quehacer filosófico nacional), como lo fueron de un gran número de otras filósofas que estudiamos y nos desarrollamos profesionalmente en México. Quiero subrayar brevemente sólo algún rasgo de cada una de las entrevistas. El énfasis que haré es en la mirada de las entrevistadas 
respecto de lo que es ser mujer y ser filósofa. Esto servirá, creo yo, para ilustrar la tercera lectura del volumen antes mencionada. Mi tratamiento de las entrevistas seguirá el orden de su aparición en el libro que nos ocupa.

Virginia Aspe actualmente es profesora-investigadora en la Universidad Panamericana y trabaja sobre textos filosóficos mexicanos de los siglos XVI al XVIII que tratan sobre ley natural y derechos humanos, sobre el problema del otro en relación con la idea de "dominio", entre otras cosas. En algún momento de la entrevista, ella dice que las mujeres estamos siempre más cerca de la realidad en nuestra teorización filosófica. Según ella, la diferencia entre hombres y mujeres se refleja en el modo en que nos aproximamos a la filosofía, pero no necesariamente en los temas que trabajamos (aunque, precisa, esto sí es distinto en la vida ordinaria).

Paulette Dieterlen, investigadora del Instituto de Investigaciones Filosóficas de la UNAM, ha centrado sus intereses de los últimos años en torno al concepto de "justicia". Esto, entre otras cosas, la llevó a escribir un libro sobre la pobreza, su libro favorito según ella misma sostiene. Al hablar sobre las mujeres y su papel en la filosofía, sostiene que el feminismo teórico está más avanzado que el práctico: quién mejor que ella a quien tanto le gustan los deportes (que suelen delimitar mundos masculinos) puede saber de esto. Pero, además, habla acerca de la desproporción que existe hoy día entre las discusiones sobre los derechos de los animales y la situación de las mujeres en el ámbito de la filosofía académica. Este apunte suyo, creo yo, es crucial el día de hoy en que, por lo que sabemos, diez mujeres al día son asesinadas de manera violenta en nuestro país.

Al narrar su historia, Kim Díaz nos dice lo difícil que es, en los Estados Unidos de América, ser mujer, mexicana y filósofa. Tres determinaciones del margen, como ella misma habla de estas propiedades. Actualmente ella trabaja en la Universidad de Texas en El Paso y se dedica a estudiar la filosofía latinoamericana, especialmente aquellas cuestiones de esta última que tienen que ver con la realidad sociopolítica de los paises de esa región del mundo. En la entrevista nos cuenta un experimento que hace con sus alumnas: les pide que cierren los ojos e imaginen a alguien que hace filosofía. Siempre, dice ella, el resultado de la imaginación arroja a un hombre con barba y pelo blanco. Ella dice que una pregunta urgente en nuestro contexto actual es "¿qué es ser hombre hoy?". Quizá de una respuesta a esta pregunta pueda surgir mucha comprensión 
acerca de la relación que prevalece entre los hombres y las mujeres en nuestras sociedades capitaslistas actuales.

La siguiente entrevistada es Maite Ezcurdia, quien - siendo aún muy joven - falleció en diciembre de 2018. A pesar de su partida anticipada, ella tuvo una vida académica intensa y dejó una importante herencia a sus estudiantes. Ella fue impulsora ferviente de la filosofía del lenguaje analítica en México y tenía un interés fuerte en la generación de grupos de investigación que terminaran por crear una comunidad filosófica nacional y latinoamericana. Ella, en la entrevista, narra que venía de una familia de mujeres fuertes. Ella misma fue una mujer fuerte. De manera determinada dice que las mujeres no queremos entrar (ni a la filosofía, ni a la academia) por cuota.

Juliana González fue directora de la Facultad de Filosofía y Letras de la UNAM y en su entrevista deja ver toda la fuerza que la constituye. La suya es una entrevista dura y crítica en la que señala muchos de los problemas que ella ve en el quehacer filosófico nacional. Entre muchas otras cosas interesantes y dignas de ser pensadas, ella dice que en México no hay una comunidad filosófica, no digamos una escuela de filosofía. Dice también que no somos buenas para "pintar la raya" en cuestiones de género. Finalmente, hace una crítica a las consecuencias negativas que ha traído consigo el SNI: desde su perspectiva, este sistema contribuye al individualismo y a la falta de creación de comunidad de investigación.

Olbeth Hansberg es investigadora del Instituto de Investigaciones Filosóficas y actualmente trabaja de manera predominante en torno a las emociones. Ella es otra mujer fuerte que ha tenido diversos cargos administrativos: fue directora del Instituto mencionado, coordinadora de Humanidades de la UNAM y, finalmente, fue también miembro de la Junta de Gobierno de esta misma universidad. En su entrevista narra su modo de llegar a la filosofía, el esfuerzo que significó para ella dedicarse a la filosofía.

María Pía Lara, profesora-investigadora de la UAM-Iztapalapa, trabaja cuestiones de ética y filosofía política. Desde su perspectiva: "Algunas personas ponen en duda si hay un pensamiento de mujeres. Por supuesto que lo hay. Lo que ocurrió en el siglo pasado, la revolución feminista, fue la única revolución global" (p. 87). Esta frase deja en claro cuál es su posición en torno a las mujeres y su papel en la filosofía.

Fernanda Navarro, simpatizante zapatista, ha dedicado sus años recientes a pensar, enseñar y hacer suya la filosofía que subyace a los planteamientos del EZLN. Su vida, tal como la narra, aunque sea de 
manera breve, en el libro que nos ocupa, es profudnamente interesante. Una mujer comprometida que nunca separó su pensamiento de su acción. Su hacer político es su pensar filosófico. Esto queda plasmado en la hermosa entrevista que está capturada en nuestro libro.

Dos mujeres más fueron entrevistadas. Paulina Rivero, profesora de la Facultad de Filosofía y Letras, muy interesada en cuestiones de bioética y actualmente coordinadora del Programa de Bioética de la UNAM. Ella narra que por cierto tiempo pensó que estudiar el feminismo no era "hincarle el diente en serio a la filosofía", y creyó que hombres y mujeres podían llegar en la filosofía hasta donde quisieran. De pronto tuvo un suceso que le cambió la mirada. Hoy día cree que una mujer tiene que luchar mucho más para encontrar un lugar en el mundo de la filosofía académica. Piensa, además, que existe una forma femenina de decir las cosas. En esto se encuentra con Virginia Aspe: ambas perciben, se percatan y sostienen que hay una sensibilidad propiamente femenina que no sólo nos acerca a los temas de la realidad, sino que nos provee de un modo de argumentar y defender nuestras ideas.

El libro cierra con la entrevista a Carmen Rovira, profesora emérita de la Facultad de Filosofía y Letras, alumna de Gaos que se preocupaba por su calidad de madre de familia. Él pensaba que ella difícilmente desarrollaría y proseguiría su careera de manera exitosa porque ser madre y ser académica son incompatibles. Ella mostró, con hechos, que ese prejuicio es falso. Carmen Rovira, mujer y, sin saberlo, feminista; una de las mujeres más tesoneras que mostró con actos, afán, empeño y compromiso que una madre, una esposa, una mujer es tan digna de aprecio y respeto en el ámbito académico e intelectual como cualquier otra persona que en él se desarrolle. Ya ella nos había enseñado que ser mujer no es una desventaja, sino, por el contrario, un valor único que nos provee con una mirada y un acercamiento a nuestro quehacer que nos permite compartirlo de un modo amoroso.

Este libro, este conjunto de entrevistas, es un documento que debe ser leído no sólo por todas las mujeres filósofas que trabajamos en este país, sino también por todos quienes hacen filosofía, por las estudiantes y por la sociedad en general. Este volumen es un primer registro del modo de estar en el ámbito de la academia de las mujeres. Ojalá nos sirva para aprender lo que tenemos que hacer y lo que tenemos que dejar de hacer; ojalá sea un incentivo más en el camino a la emancipación plena de la academia, a la construcción de un mundo parejo donde todas 
quepamos y podamos desarrollarnos de manera libre y comprometida con las otras.

Ángeles Eraña

Universidad Nacional Autónoma de México

mael@filosoficas.unam.mx 
